\title{
GRUPO DE APOIO À INTEGRAÇÃO COMUNITÁRIA DE IMIGRANTES EM PORTO ALEGRE: RELATO DE EXPERIÊNCIA
}

\author{
Nathália dos Santos Lobo ${ }^{1}$ \\ João Luís Almeida Weber ${ }^{2}$ \\ Alice Einloft Brunnet ${ }^{3}$ \\ Laura Teixeira Bolaséll ${ }^{4}$
}

\begin{abstract}
Resumo: $\mathrm{O}$ presente artigo trata de um relato de experiência sobre um grupo de apoio destinado a imigrantes e refugiados, realizado entre agosto e dezembro de 2015 em Porto Alegre, Rio Grande do Sul. Este grupo objetivou oferecer um espaço aberto onde os participantes pudessem discutir livremente questôes relacionadas às dificuldades enfrentadas durante o processo migratório. O grupo foi composto por imigrantes de diferentes nacionalidades como senegaleses, haitianos, marroquinos e ganeses, todos homens e em situação de imigração econômica. As principais demandas que emergiram e foram desenvolvidas no decorrer das sessôes foram referentes ao trabalho, à qualificação profissional, à dificuldade de encontrar moradia, ao racismo, à saudade da família, à religião, aos planos para o futuro no Brasil, dentre outras. Além destas temáticas, também houve troca cultural, compartilhamento de experiências, o desenvolvimento de habilidades para enfrentamento de situaçóes difíceis, o suporte social e o apoio com informaçôes de ordem prática. O maior desafio encontrado no decorrer dos encontros foi a barreira idiomática e a adesão dos participantes.
\end{abstract}

Palavras-chave: Grupo de apoio. Imigração. Relato de experiência.

1 Graduanda em Psicologia pela Pontifícia Universidade Católica do Rio Grande do Sul e bolsista de Iniciação Científica do grupo de pesquisa Identidades, Narrativas e Comunidades de Prática. E-mail: nathalia.lobo@acad.pucrs.br

2 Mestrando em Psicologia pelo Programa de Pós-Graduação em Psicologia da Pontifícia Universidade Católica do Rio Grande do Sul. E-mail: jlweber27@gmail.com

3 Mestranda em Psicologia pelo Programa de Pós-Graduação em Psicologia da Pontifícia Universidade Católica do Rio Grande do Sul. E-mail: brunnetalice@gmail.com

4 Graduanda em Psicologia pela Pontifícia Universidade Católica do Rio Grande do Sul e bolsista de Iniciação Científica do grupo Cognição, Emoção e Comportamento. E-mail: laura.bolasell@acad.pucrs.br 


\title{
SUPPORT GROUP FOR COMMUNITY INTEGRATION OF IMMIGRANTS IN PORTO ALEGRE: AN EXPERIENCE REPORT
}

\begin{abstract}
The following article is an experience report on a support group for immigrants and refugees, which occurred between August and December 2015 in Porto Alegre, Brazil. The group aimed to offer an open space where the participants could freely discuss issues related to the migration process. The group was composed by immigrants of different nationalities, such as Senegalese, Haitian, Moroccan and Ghanaian, all male and in situation of economic immigration. The main demands that emerged and developed during the sessions were related to labor, professional qualification, housing, racism, lack of family, religion and the future in Brazil, among others. Besides these issues, the group provided cultural exchange, share of experiences, development of skills for coping with difficult situations, social support and the supply of practical information, etc. The biggest challenges faced during the meetings were the language barrier and the adhesion of the participants.
\end{abstract}

Keywords: Support group. Immigration. Experience report.

\section{INTRODUÇÃO}

A imigração é um fenômeno global que ocorre desde que existe registro sobre a história dos grupos humanos, sendo este um processo pelo qual culturas influenciam-se e tornam-se mais próximas através do comércio, da comunicação entre pessoas e do intercâmbio de informação e ideias. Entretanto, nas últimas décadas, o processo de conexões globais vem se intensificando devido a avanços tecnológicos nas telecomunicações e no incremento de interdependências financeiras e econômicas, tornando-se um dos mais importantes desafios para os sistemas políticos, econômicos e sociais do mundo (PIZZINATO, 2003). Os desastres naturais e a pobreza estão entre os principais motivos de imigração. As possibilidades de manutenção da vida e/ou sua melhoria estão historicamente associadas às possibilidades econômicas e laborais, que ainda figuram como elementos de atração e de expulsão (CARDOSO, 2002).

O sistema migratório pode ser entendido como uma associação, dotada de certa intenção e acompanhada de um denso tecido de inter-relações sócio-políticoeconômico e cultural, que se estabelece entre uma região receptora de imigração e um conjunto de países emissores de emigração (PIZZINATO; SARRIERA, 2004). Este fenômeno pode ser entendido como um plano de mudanças sociais como aspirações e emancipações políticas, religiosas e identitárias das sociedades envolvidas. É uma dinâmica que não possui um só vetor e nem um só espaço e tempo, alimentando-se por múltiplos processos do mundo contemporâneo (TEDESCO; GRZYBOVSKI, 2011). Desta forma, os marcadores antropológicos de fronteiras, tais como costumes, nacionalismo, idioma e ideologias apresentamse ressignificados, - por vezes relativizados, por vezes recrudescidos - impactando na definição dos conceitos de identidade e de cultura em relação a esses povos migrantes. Questões que pareciam óbvias, como a própria nacionalidade, contemporaneamente podem exigir um sentido mais subjetivo (SARRIERA, 2010) 
e seus principais desdobramentos psicológicos são as negociações identitárias que supõem, ou seja, como as pessoas pensam sobre si em relação ao meio social (GARCÍA-RAMÍREZ et al., 2002).

O Brasil é um país composto principalmente por imigrantes, devido às diversas ondas imigratórias que ocorreram em diferentes momentos da história desde o início da colonização do Brasil em 1500 pelos portugueses (AMARAL; FUSCO, 2005). Atualmente, o país está presenciando um novo fluxo migratório, sobretudo de regiões da América Latina e da África. Segundo dados do Department of Economic and Social Affairs of the United Nations (2015), a população imigrante no Brasil cresceu de 593.000 em 2010 para 714.000 em 2015, representando um crescimento de $20,4 \%$ em cinco anos. Este incremento pode ser associado ao desenvolvimento da economia brasileira até 2010, pelo envolvimento brasileiro em missões da ONU e pela ausência de políticas agressivas em relação a imigrantes.

Segundos dados da Polícia Federal obtidos pelo portal G1 (VELASCO; MANTOVANI, 2016), o número de imigrantes registrados em solo nacional aumentou $160 \%$ em dez anos. Em 2015, a maioria desta população estrangeira era composta por haitianos, totalizando 14.535 pessoas de origem haitiana registradas pela Polícia Federal no referido ano. Esta também foi a população que apresentou o crescimento mais significativo nos últimos cinco anos, passando de 481 entradas em 2011 para 14.535 em 2015, o que representa um aumento de mais de 30 vezes.

O gráfico abaixo mostra o ranking de países de origem dos imigrantes que chegaram ao país em 2015 (VELASCO; MANTOVANI, 2016). 
Gráfico 1 - Ranking de países de origem dos imigrantes que chegaram ao Brasil em 2015

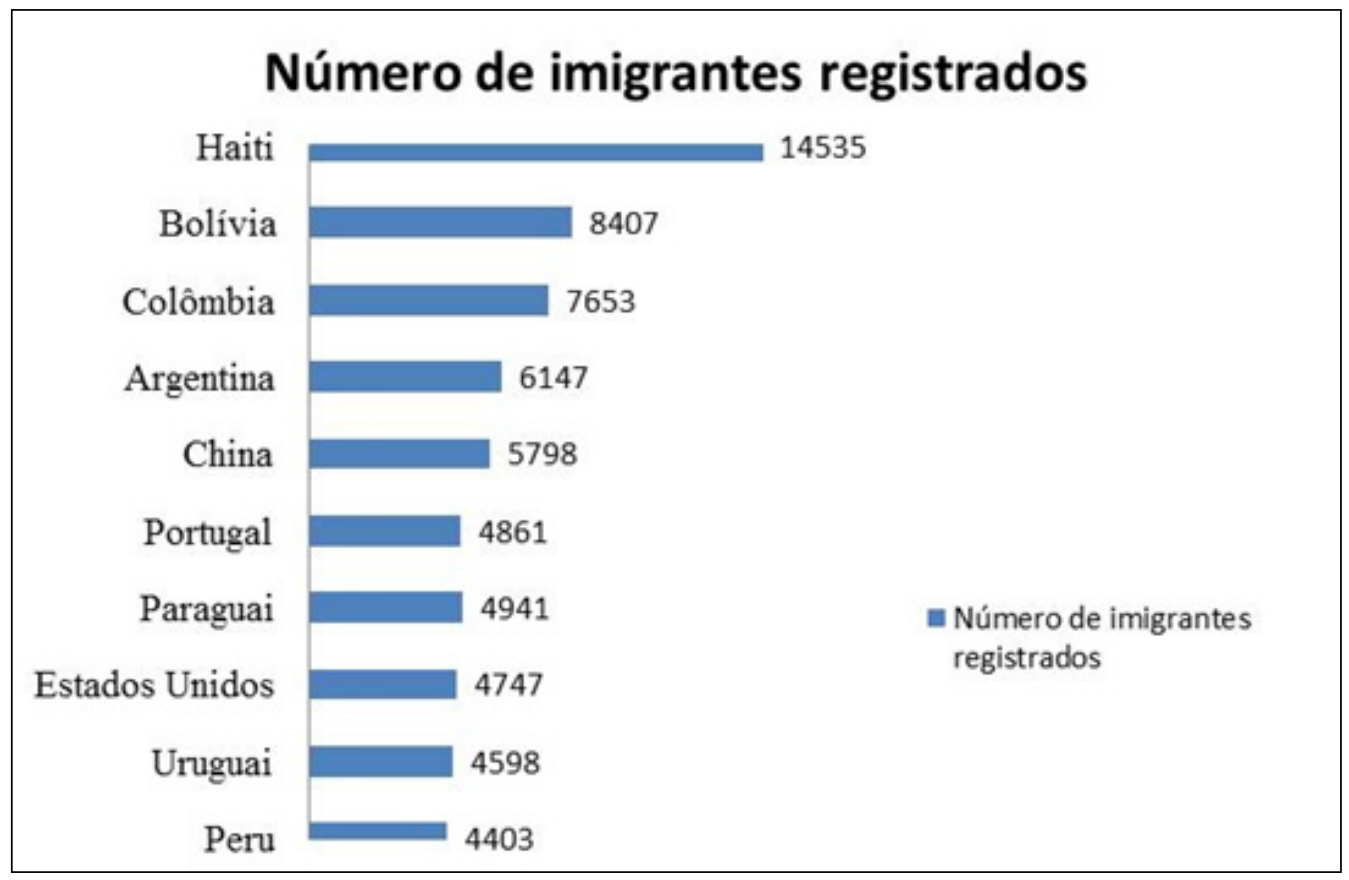

Fonte: Dados da Polícia Federal obtidos pelo portal G1 (VELASCO; MANTOVANI, 2016).

Neste contexto, o estado do Rio Grande do Sul figura como um dos destinos mais visados, concentrando boa parte desta população que realizou o processo migratório recentemente. Muitos empresários gaúchos buscaram a mão de obra imigrante como forma de combater a escassez de força de trabalho nas indústrias do interior gaúcho. Assim, muitas empresas enviaram transporte para buscar os recém-chegados imigrantes para a região, aumentando consideravelmente esta população no Rio Grande do Sul (ROLLSING; TREZZI, 2014). A mídia gaúcha estima que atualmente residam no estado cerca de 7 mil haitianos e 4 mil africanos, conforme reportagem publicada no jornal Zero Hora em 16 de agosto de 2014 (ROLLSING; TREZZI, 2014).

Segundo um estudo realizado por Tedesco e Grzybovski (2011) com imigrantes senegaleses, embora as motivações de imigração sejam financeiras e por busca de melhor qualidade de vida, o salário só é utilizado para a subsistência, sendo sua maior parte repassada para o país de origem. Tais remessas financeiras são uma forma de manter as relações dos imigrantes com os familiares que não migraram. Praticamente todos os imigrantes possuem vínculos familiares no país de origem. Por tal motivo, compreende-se que a imigração é um processo que implica tanto as pessoas que migram como as que ficam nos países, havendo projetos e sonhos de ambas as partes, o que torna esta ação familiar, afetiva e econômica (TEDESCO; GRZYBOVSKI, 2013). 
Em entrevistas realizadas por uma pesquisa da Universidade de Minas Gerais (COTINGUIBA, 2014), haitianos relataram seus principais motivos para terem imigrado para o Brasil. Estes motivos tangenciam o tema de imigração econômica, sendo para ajudar a família que permaneceu no Haiti, por terem perdido tudo que tinham no terremoto de 2010, por causa da violência no Haiti, para arrumar emprego, dentre outros. Com relação à vida no Brasil, os haitianos relataram apresentarem dificuldades para encontrar um emprego, muitas vezes por não dominarem a língua portuguesa. Para aqueles que estão trabalhando, os salários são baixos e as condições de trabalho difíceis e, por vezes, abusivas (COTINGUIBA, 2014).

Desta forma, os grupos de apoio têm como objetivo auxiliar pessoas durante períodos de ajustamento a mudanças, no tratamento de crises ou na adaptação a novas situações, como no caso dos imigrantes (ALVAREZ et al., 2012). Os grupos promovem a criação de um ambiente de compartilhamento de experiências e sentimentos, a compreensão mútua entre os participantes, a aprendizagem de novos comportamentos em clima de compartilhamento e aceitação e o acesso a recursos para lidar com pessoas que vivem situações de crise, elevando a autoestima e a autoconfiança de seus participantes (OLIVEIRA et al., 2010). Assim, os grupos de apoio para imigrantes e refugiados podem facilitar o processo de adaptação ao novo contexto, aumentando o repertório dos participantes para lidar com novas situações.

A literatura específica referente a grupos de apoio a imigrantes ainda é escassa, e não foram encontrados artigos empíricos sobre o tema. Há, no entanto, literatura teórica referente ao tema de Multicultural Counseling, que é uma forma de aconselhamento adaptado a diferentes contextos culturais. Manuais sobre o tema publicados pela American Association for Counseling and Development (1989) abordam as questões que devem ser trabalhadas em aconselhamento a imigrantes. Sue et al. (1992) explicam que multicultural conseling tem como público alvo minorias étnicas (onde entrariam os imigrantes) e raciais, mulheres, gays, lésbicas e outras populações. Entende-se que imigrantes e refugiados geralmente encontram diversas dificuldades ao ingressar no novo país e, muitas vezes, desconhecem seus direitos e como agir nele. Por isso, os grupos de apoio a essas populações são focados na passagem e transmissão de informação.

Além disso, outros temas recorrentes em grupos de imigrantes envolvem questões de trabalho, exigindo que os facilitadores do grupo estejam preparados para auxiliar na produção de currículo, na busca de empregos e no acompanhamento de imigrantes nas entrevistas. A conscientização sobre os direitos que eles possuem e sobre as leis trabalhistas do local também são temas importantes a serem abordados e discutidos com o grupo. Além disso, deve-se atentar para questões que mobilizam emocionalmente o grupo, como o contato com a família, a saudade e o planejamento do futuro. A maioria dos imigrantes manda uma parte do dinheiro que consegue no novo país para a sua família que ficou e muitos têm em mente trazer seus familiares em algum momento para compartilhar da nova vida (TEDESCO; GRZYBOVSKI, 2011). Por isso, trabalhar com o planejamento de gastos e economia também é 
interessante. Assim, o grupo relatado neste estudo se propôs a oferecer um espaço aberto, no qual os participantes pudessem discutir livremente questões relacionadas às dificuldades enfrentadas durante o processo migratório.

\section{MÉTODO}

Este artigo apresenta o relato de experiência sobre a organização de um grupo de apoio para imigrantes em um Centro de Acolhimento para imigrantes de Porto Alegre, no estado do Rio Grande do Sul. Os relatos, conforme o modelo de Hoga e Abe (2000), informam experiências vivenciadas contendo tanto impressões reais, psicológicas e críticas que sejam pertinentes ao tema.

Os encontros do grupo ocorreram quinzenalmente durante seis meses, entre agosto e dezembro de 2015, totalizando 12 encontros com duração média de uma hora cada. Estes encontros foram mediados por psicólogos e estudantes de Psicologia, sendo realizados em um espaço cedido pelo Centro Ítalo-Brasileiro de Assistência e Instrução às Migrações de Porto Alegre. O grupo era aberto e ocorria antes da aula de português fornecida pela instituição, sendo que o número de participantes variava de 5 a 15 por encontro. Os participantes eram imigrantes de diferentes nacionalidades, como senegaleses, haitianos, marroquinos e ganeses, e foi composto por homens com idades entre 19 e 50 anos e em situação de imigração econômica. O grupo também se propôs a receber refugiados, entretanto nenhum dos participantes estava nesta situação. Devido à pluralidade de nacionalidades e idiomas, o português fora estabelecido como o principal idioma de comunicação entre os participantes do grupo e os facilitadores. Inicialmente, foram levantadas as principais demandas dos participantes, as quais foram trabalhadas no decorrer das sessões com a utilização da estratégia participativa.

\section{RESULTADOS E DESCRIÇÃO DO GRUPO}

\section{Trabalho e qualificaçáo profissional}

O principal tema desenvolvido no grupo se referia às questões laborais. Como a maioria dos imigrantes participantes do grupo estava em situação de imigração econômica, a demanda mais recorrente era sobre a insatisfação dos participantes com seus empregos e salários, assim como busca por oportunidades de inserção no mercado, no caso dos imigrantes desempregados. Deste modo, os facilitadores precisaram trabalhar o descontentamento e as expectativas dos participantes sobre seus trabalhos, além de sugerir cursos de aperfeiçoamento (como cursos técnicos e superiores) como uma forma de possibilitar uma ascensão para um emprego que oferecesse melhores condições ou que correspondesse aos planos individuais dos imigrantes. Tais cursos foram uma demanda solicitada pelos imigrantes e houve adesão e busca por oportunidades a partir das discussões que ocorreram no grupo. Entretanto, outros imigrantes argumentaram que não possuíam condições financeiras nem tempo para fazer tal atividade. Isso se dá porque os imigrantes, 
muitas vezes, trabalham nos chamados subempregos, principalmente em obras, frigoríficos, limpeza etc. (ZAMBERLAN et al., 2014). Além disso, em consonância com o encontrado na literatura (TEDESCO; GRZYBOVSKI, 2011), a grande maioria utiliza o salário para subsistência, uma vez que enviam o restante de seus salários para suas famílias no país de origem, sendo que muitos relataram sustentar esposas, filhos, pais, irmãos etc. As remessas financeiras mantêm vivas as relações entre quem partiu e quem ficou no país de origem, atestando a densidade emotiva e simbólica das relações familiares ou não que são mantidas (TOLENTINO, 2009). Ainda, elas manifestam vínculos sociais de longa duração e contribuem para manter/alimentar múltiplas relações que viabilizam os fluxos migratórios, expressam a consciência da distância e a frustração da impossibilidade de contato face-a-face (TEDESCO; GRZYBOVSKI, 2013).

Um fenômeno importante observado a partir do desenvolvimento das questões referentes ao trabalho foi a emersão da figura de um líder. Neste caso, o líder era um participante que estava há mais tempo e possuía um emprego considerado de prestígio. Segundo Pichon-Rivière (2005), uma liderança como a exercida por este participante é compreendida como uma facilitadora da mudança, auxiliando o(s) coordenador(es) e o grupo na execução da tarefa (no caso, a discussão de temas pertinentes aos participantes). Este participante tornou-se, no decorrer das sessões, uma referência aos outros participantes e servia como principal elo entre os facilitadores e o grupo. A presença desta liderança positiva agregou ao grupo experiência e trouxe aos outros participantes esperança, pois viam ele como "um caso de sucesso". Desta forma, muitas vezes, os participantes olhavam para esta figura antes de falar, como quem espera que esta pessoa tenha a resposta.

\section{Violência}

Os participantes trouxeram em diversos encontros situações de violência que enfrentaram em território brasileiro, tais como perda de documentos, assaltos e o medo de sofrerem represálias. Sempre que estes assuntos eram abordados havia grande mobilização do grupo, tanto para contar situações parecidas quanto para apoiar o colega. Em um dos encontros, um dos pacientes relatou não estar conseguindo sair de casa após ter sofrido um assalto. Houve, assim, uma grande mobilização por parte dos participantes para encorajar o referido participante a sair de casa. A intervenção dos facilitadores também teve o intuito de reforçar a ideia de que ele precisava reinserir-se à sociedade, dando dicas de segurança básica, orientando sobre como acionar a polícia e a fazer um Boletim de Ocorrência e, principalmente, ajudando o participante a pensar que isto foi um fato isolado, que poderia acontecer com qualquer um. Assim, houve uma tentativa do grupo de reforçar o fato de ele ter vindo ao grupo mesmo com medo e encorajá-lo a continuar vindo.

Outra situação que gerou mobilização no grupo foi um atentado violento contra um imigrante haitiano ocorrido alguns dias antes de um dos encontros do grupo. Neste encontro, havia mais participantes que o usual (15, ao todo) e 
este assunto foi o principal do encontro. Muitos relataram ter medo de sair na rua. Um dos participantes chegou a dizer: "Todos os dias saímos na rua e não sabemos se iremos voltar vivos". Assim, os imigrantes expressaram seus medos e angústias em relação à própria segurança e de seus companheiros, gerando bastante identificação entre os participantes. Assim, estabeleceu-se um diálogo entre todos os componentes do grupo a fim de compartilhar a experiência, mas também de apoiar o sofrimento dos outros participantes, intercambiando conselhos, apoio instrumental e emocional e orientações práticas no campo legal. Além da identificação e da empatia, o compartilhamento destas emoções pode suscitar reflexões entre os participantes sobre seus planos para o futuro no Brasil.

\section{Racismo}

Para a discussão da temática da discriminação racial, o grupo de facilitadores utilizou, como disparador para discussão, um vídeo que mostra a vida de um imigrante negro e africano e de um imigrante branco e europeu, ambos morando na mesma cidade e estudando na mesma universidade. No vídeo fica explícito o tratamento diferente que ambos recebem e as diversas facetas de racismo vivenciadas pelo imigrante africano. Após o vídeo, o grupo que era majoritariamente formado por imigrantes negros, iniciou-se uma discussão onde alguns relatavam nunca terem sofrido racismo no Brasil, enquanto outros diziam já ter sofrido este preconceito. Trabalhou-se a questão de que o racismo muitas vezes pode aparecer de formas não tão explícitas.

Segundo Lima e Vala (2004), estas formas compõem o que se chama de racismo cordial, que é a uma forma de discriminação contra pessoas não brancas, que muitas vezes é expressa através de uma polidez superficial que reveste atitudes discriminatórias. O racismo cordial é expresso através de piadas, ditos populares e "brincadeiras" de cunho racial. O termo fora cunhado a partir de um estudo (TURRA; VENTURI, 1995) realizado junto a uma amostra representativa da população brasileira, o qual verificou a incidência de racismo autodeclarado e aplicou uma escala de racismo indireto, a fim de comparar os resultados. Verificouse que $89 \%$ da amostra declarou não existir racismo no Brasil e não ser racista. Turra e Venturi (1995) utilizaram então uma escala menos direta com 12 itens como "Negro bom é negro de alma branca", "Negro, quando não faz besteira na entrada, faz na saída", dentre outros, e verificaram que mais de $50 \%$ da amostra pesquisada concorda com afirmativas deste tipo. De uma maneira geral, $83 \%$ da população entrevistada concorda, em algum nível, com os itens da escala de racismo cordial, confirmando o caráter indireto, velado e hipócrita do racismo no Brasil. O racismo cordial e suas expressões, segundo Lima e Vala (2004), são tão ou mais danosas e nefastas do que as expressões mais abertas e flagrantes, uma vez que, por serem mais difíceis de ser identificadas, são também mais difíceis de ser combatidas.

No grupo, os imigrantes chegaram a um acordo de que o Brasil é um país que possui indivíduos racistas, mas que, porém, eles não são a maioria e os imigrantes diziam, de certa forma, suportar estas atitudes por não serem tão recorrentes. 
Os facilitadores do grupo ainda trouxeram a questão de direitos humanos para a discussão e apontaram que qualquer ato racista é um crime no Brasil, e por fim apontaram como os imigrantes poderiam denunciar quando sofressem tal discriminação.

\section{Saudade da família e planos para o futuro no Brasil}

Quando questionados sobre seus planos para o futuro, muitos inicialmente manifestavam querer visitar suas famílias no país de origem, mas estavam incertos sobre isto ser possível em um futuro próximo, alegando que "o dólar está muito caro". Sobre o futuro no Brasil, os participantes também divergiram em suas falas. Alguns referiram querer continuar no país, terem sonho de construir uma família aqui ou trazer a sua do país de origem para o Brasil. Outros participantes manifestaram interesse em ir para outros países que, segundo suas percepções, oferecem melhores condições para imigrantes, como os Estados Unidos. Por fim, a terceira opção levantada pelos participantes é a de voltar para seus países de origem.

A saudade das famílias deixadas no país de origem ou em outros países também foi um tema que gerou muita mobilização durante as sessões. Um dos participantes, em uma das sessões, referiu sentir falta dos filhos, emocionando-se. Houve, então, uma mobilização geral no grupo após este relato, deixado todos parecendo pensativos, olhando para baixo em unanimidade. Logo, o participante que assumiu o papel de líder do grupo sugere-lhe, então, formas de economizar dinheiro para trazer-lhes para o Brasil.

Uma das soluções encontradas pelos imigrantes para aliviar a saudade de suas famílias e de seus países de origem é através de festas e eventos típicos. Assim, em vários encontros, os participantes organizavam-se entre si para irem às festas e eventos sociais promovidos pelas associações de imigrantes.

\section{Religiáo}

No que se refere à religião dentro do grupo, verificou-se que os participantes senegaleses e o ganês eram islâmicos. Os haitianos, por sua vez, relataram serem adeptos de religiões evangélicas. Verificou-se que a religião configura como uma rede de apoio para estes imigrantes, sendo o primeiro lugar onde recorriam ajuda. Além disso, grande parte da rede dos participantes se dava através da religião, formando comunidades de compartilhamento de hábitos culturais, como religiosos e alimentares, compondo um meio de convivência e lazer para os participantes. De acordo com Tedesco e Grzybovski (2013), o campo religioso facilita a promoção de integração e consolação moral em razão das condições objetivas de vida de um imigrante distante de seus familiares e de seu país. Além disso, Lotufo Neto (1996) identificou que a religiosidade está associada à melhor saúde mental. $\mathrm{O}$ autor também observou menor abuso e dependência de álcool e drogas em população religiosa. 
Durante muitos encontros, a questão religiosa foi tratada como um tabu pelos participantes do grupo, que pareciam evitar entrar neste assunto mudando de tópico ou se comportando de maneira inquieta quando o assunto surgia. Entretanto, em um encontro, esta questão foi explorada a partir de um atrito que surgiu dentro do segmento islâmico do grupo. O participante marroquino relatou ter deixado a religião islâmica por motivos pessoais, o que gerou uma visível incomodação em um dos senegaleses. Este tentou repreender o participante marroquino, gerando um grande envolvimento dos participantes e dividindo opiniões. A partir disto, foi possível adentrar em questões culturais mais profundas como questões de estrutura social, uma vez que a discussão tangenciou assuntos como a ingestão de álcool e de certo alimentos, o uso de determinadas roupas pelas mulheres, o livrearbítrio, dentre outras. Apesar de o atrito ter gerado um inicial desconforto entre os participantes, o assunto rendeu um importante diálogo inter-religioso e suscitou nos participantes uma reflexão positiva acerca de suas práticas, a fim de tornálas mais conscientes. Os facilitadores, neste caso, tiveram o papel de não deixar a discussão tomar um caráter pessoal e/ ou agressivo, buscando generalizar o assunto a nível social e não individual, trazendo aspectos positivos e negativos de várias religiões diferentes e propondo, assim, uma reflexão mais profunda.

\section{Trocas culturais}

Verificou-se no grupo uma alta diversidade cultural, linguística e religiosa, possibilitando uma intensa troca cultural entre os participantes e entre os participantes com os facilitadores. As trocas culturais e o compartilhamento de experiências possibilitam conhecer novas realidades, pensamentos e visões, flexibilizando as cognições em direção de uma melhor aceitação da pluralidade.

No grupo, as trocas culturais foram possíveis principalmente pela curiosidade expressa pelos imigrantes em entender determinadas questões sobre a cultura brasileira. Em contrapartida, eles apresentavam muito orgulho em mostrar imagens, descrever comidas, mostrar músicas, e falar sobre seus países. Neste momento, também havia um grande saudosismo, o qual era acompanhado pela vontade de participar e realizar festas e encontros no Brasil, com a temática do país de origem dos imigrantes, podendo, assim, aproximar estes imigrantes das suas culturas nativas.

Uma demanda que surgiu no grupo refere-se à promoção de atividades mais lúdicas como recitar poemas, tocar músicas, organizar peças de teatro, sobretudo contendo conteúdo dos países de origem. Os participantes referiram querer utilizar aquele tempo como forma de distração e de prática do português, o que foi um dado surpreendente que não fora encontrado na literatura. Isto demonstra uma carência por parte de populações estrangeiras em encontrar opções de lazer e de expressão artística nas comunidades de acolhida. Muitas vezes estes espaços são supridos por eventos promovidos pela própria comunidade imigrante, pela religião e, muitas vezes, pelo próprio trabalho em si, uma vez que alguns participantes referiam que usavam o trabalho como forma de distração da realidade. 


\section{CONCLUSÓES}

A partir da experiência relatada, observou-se que o grupo foi se tornando, de forma gradual, um espaço que favoreceu o compartilhamento de experiências, o desenvolvimento de habilidades para enfrentamento de situações difíceis, o suporte social e o apoio com informações de ordem prática, assim como o estabelecimento de uma rede entre os imigrantes e os facilitadores. Todos estes benefícios são importantes para melhorar a qualidade de vida, a inserção de imigrantes em contextos diferentes e diminuir o estresse aculturativo, ou seja, o estresse que emerge em uma situação intercultural e corresponde a um processo de adaptação que pode ser tanto positivo quanto negativo (BERRY, 1990). Também é destacada a importância do grupo para a criação de novas redes entre os próprios imigrantes, assim como um espaço de reflexão sobre temáticas que atravessam a vida destes indivíduos e, por muitas vezes, não podem ser elaboradas ou compartilhadas. Segundo Beccegato (1995) e Sayad (2008), é importante que se adentre em problemáticas cognitivas, afetivas, sociais e que se trabalhe no desenvolvimento de um pensamento aberto, flexível, inclusivo, que valorize os comportamentos reconhecidos no diálogo e no encontro. Assim, o grupo figurou como um espaço promotor desta troca que permite uma melhor inclusão na sociedade de pessoas estrangeiras.

Ainda que o uso da língua portuguesa pudesse ser entendido como um elemento dificultador da melhor expressão e participação dos imigrantes, também propiciava mais potencial de integração com outros imigrantes de outras nacionalidades e com os facilitadores brasileiros. Observou-se uma maior ligação e vinculação entre os imigrantes de mesma nacionalidade ou que falavam a mesma língua, uma vez que os que possuíam mais domínio do idioma faziam o intermédio e a tradução do que o participante dizia para o grupo e vice-versa. Outro desafio encontrado foi a dificuldade de adesão dos participantes, o que fez com que o número de participantes fosse inconstante e atrapalhasse o processo de vinculação. Acreditamos que isso ocorreu devido ao espaçamento entre os encontros e pela barreira idiomática, que já abordamos.

Além disso, verificou-se uma grande lacuna na literatura brasileira sobre o tema dos grupos de apoio para imigrantes e refugiados. Como são temáticas ainda muito emergentes, é preciso que se desenvolvam estudos mais aprofundados sobre como estruturar grupos de apoio para esta população específica, pensando na promoção de qualidade de vida e na melhor inserção da referida população em seu novo contexto, levando em consideração as particularidades do Brasil, enquanto país que apenas recentemente virou foco migratório de pessoas advindas dos países citados aqui neste estudo. 


\section{REFERÊNCIAS}

ALVAREZ, S.Q.; GOMES G.C.; OLIVEIRA, A. M. N; XAVIER, D. M. Grupo de apoio/ suporte como estratégia de cuidado: importância para familiares de usuários de drogas. Revista Gaúcha de Enfermagem, Porto Alegre, v. 33, n. 2, p. 102-108, jun. 2012.

AMARAL, E. F.; FUSCO, W. Shaping Brazil: The Role of International Migration. Washington: Migration Policy Institute, 2005.

AMERICAN ASSOCIATION FOR COUNSELING AND DEVELOPMENT. Bylaws. Alexandria, VA: Author, 1989.

BERRY, J. W. Human Behavior in Global Perspective: An Introduction to CrossCultural psychology. Boston, MA: Allyn \& Bacon, 1990.

CARDOSO, A. F. Migrações internacionais: os blocos regionais e a mobilidade mundial de mão-de-obra. São Paulo em Perspectiva, v. 16, n. 2, p. 112-124, 2002.

COTINGUIBA, G. C. Imigração haitiana para o Brasil: a relação entre trabalho e processos migratórios. 2014. Dissertação (Mestrado em História e Estudos Culturais) Departamento de História, Universidade Federal de Rondônia, Porto Velho, 2014.

GARCÍA-RAMÍREZ, M.; MARTÍNEZ-GARCÍA, M.; SANTOLAYA-SORIANO, F. Integración social y empleo de inmigrantes. Sevilla (ES): Universidad de Sevilla, 2002.

HOGA, L. A. K.; ABE, C. T. Relato de experiência sobre o processo educativo para a promoção da saúde de adolescentes. Revista da Escola de Enfermagem da USP, São Paulo, v. 34, n. 4, p. 407-412, dez. 2000.

LIMA, M. E. O.; VALA, J. As novas formas de expressão do preconceito e do racismo. Estudos de Psicologia, v. 9, n. 3, p. 401-411, 2004.

LOTUFO NETO, F. Psiquiatria e religião: a prevalência de transtornos mentais entre ministros religiosos. 1996. Tese (Livre-docência) - Faculdade de Medicina, Universidade de São Paulo, São Paulo, 1996.

DEPARTMENT OF ECONOMIC AND SOCIAL AFFAIRS OF THE UNITED NATIONS. Trends in International Migrant Stock: Migrants by Destination and Origin. 2015. Disponível em: < http://www.un.org/en/development/desa/population/ migration/data/estimates2/estimates15.shtml.>. Acesso em 20 jul. 2016.

OLIVEIRA, L. M. A. C.; MEDEIROS, M.; BARBOSA, M. A.; SIQUEIRA, K. M.; OLIVEIRA, P. M. C.; MUNARI, D. B. O acolhimento de familiares de pacientes internados em UTI: a tecnologia de grupo como estratégia para o cuidado de enfermagem. Revista da Escola de Enfermagem da USP, v. 44, v. 2, p. 429-436, 2010. PICHON-RIVIÈRE, E. O processo grupal. 7. ed. São Paulo: Martins Fontes, 2005. PIZZINATO, A. Psicologia em Questão: Reflexões Sobre A Contemporaneidade. Porto Alegre: EdiPUCRS, 2003. 
PIZZINATO, A.; SARRIERA, J. C. Identidade étnico-nacional e competência social em escolas de Porto Alegre. Aletheia, v. 19, n. 1, p. 7-20, 2004.

ROLLSING, C.; TREZZI, H. Novos imigrantes mudam o cenário do Rio Grande do Sul. Zero Hora, Porto Alegre, 16 ago. 2014. Disponível em: <http://zh.clicrbs.com. $\mathrm{br} / \mathrm{rs} /$ noticias/noticia/2014/08/novos-imigrantes-mudam-o-cenario-do-rio-grande-dosul-4576728.html>. Acesso em: 20 jul. 2016

TEDESCO, J. C.; GRZYBOVSKI, D. Senegaleses no norte do Rio Grande do Sul: integração cultural, trabalho e dinâmica migratória internacional. Revista Espaço Pedagógico, Passo Fundo, v. 18, n. 2, p. 336-355, jul./dez. 2011.

TEDESCO, J. C.; GRZYBOVSKI, D. Dinâmica migratória dos senegaleses no norte do Rio Grande do Sul. Revista Brasileira de Estudos de População, São Paulo, v. 30, n. 1, 2013.

TOLENTINO, N. C. Migrações, remessas e desenvolvimento: o caso africano. Instituto Superior de Economia e Gestão. Socius working papers, n. 09, 2009. Disponível em: <http://www.repository.utl.pt/bitstream/10400.5/1884/1/WP_9_2009.pdf>. Acesso em: 20 jul. 2016.

TURRA, C.; VENTURI, G. Racismo cordial: a mais completa análise sobre preconceito de cor no Brasil. São Paulo: Ática, 1995.

SARRIERA, J. C. Psicologia Comunitária: Estudos Atuais. Porto Alegre: Sulina, 2010.

SUE, D. W; ARREDONDO, P.; McDAVIS, R. J. Multicultural Counseling Competencies and Standards: A Call to the Profession. Journal of Counseling \& Development, v. 70, p. 477-486, mar./abr. 1992.

VELASCO, C.; MANTOVANI, F. Em 10 anos, número de imigrantes aumenta 160\% no Brasil, diz PF. G1, São Paulo, 25 jun. 2016. Disponível em: <http://g1.globo.com/ mundo/noticia/2016/06/em-10-anos-numero-de-imigrantes-aumenta-160-no-brasil-dizpf.html>. Acesso em: 20 jul. 2016.

ZAMBERLAM, J.; CORSO, G.; CIMADON, J.M.; BOCCHI, L. Os novos rostos da imigração no Rio Grande do Sul. Porto Alegre: Solidus, 2014. 